\title{
Determining the slag fraction, water/binder ratio and degree of hydration in hardened cement pastes
}

\begin{abstract}
M.H.N. Yio ${ }^{*}$, J.C. Phelan, H.S. Wong and N.R. Buenfeld
Concrete Durability Group, Department of Civil and Environmental Engineering, Imperial College London, SW7 2AZ, $U K$

Abstract

A method for determining the original mix composition of hardened slag-blended cement-based materials based on analysis of backscattered electron images combined with loss on ignition measurements is presented. The method does not require comparison to reference standards or prior knowledge of the composition of the binders used. Therefore, it is well-suited for application to real structures. The method is also able to calculate the degrees of reaction of slag and cement. Results obtained from an experimental study involving sixty samples with a wide range of water/binder (w/b) ratios ( 0.30 to 0.50 ), slag/binder ratios ( 0 to 0.6 ) and curing ages ( 3 days to 1 year) show that the method is very promising. The mean absolute errors for the estimated slag, water and cement contents $\left(\mathrm{kg} / \mathrm{m}^{3}\right), \mathrm{w} / \mathrm{b}$ and s/b ratios were $9.1 \%, 1.5 \%, 2.5 \%, 4.7 \%$ and $8.7 \%$, respectively. $91 \%$ of the estimated $w / b$ ratios were within 0.036 of the actual values.
\end{abstract}

Keywords: Backscattered electron imaging; Image analysis; Slag; Water-binder ratio; Degree of hydration

${ }^{*}$ Corresponding author. Tel: +44 (0)20 7594 5345; Fax: +44 (0)20 72252716

E-mail address: marcus.yio11@imperial.ac.uk (M.H.N. Yio). 


\section{Introduction}

Ground-granulated blastfurnace slag (GGBS) is increasingly being used in concrete due to its many benefits. For example, partial replacement of Portland cement with slag is commonly specified for structures exposed to sea-water because slag greatly enhances the resistance of concrete to chloride ingress and therefore delays the time until embedded reinforcement starts to corrode. Slag also reduces the total heat released and peak temperature reached during the early life of thick concrete elements and therefore is specified to reduce the risk of early-age thermal cracking. The use of slag in concrete is also motivated by the desire to reduce the environmental impact of Portland cement clinker and to produce sustainable low-carbon concrete.

To ensure the performance of hardened concrete, minimum and maximum limits of slag replacement of Portland cement and the mass ratio of water to total cementitious materials (w/b) are usually specified. Occasionally, disputes have arisen about the actual amount of slag present, or the w/b ratio, in an existing structure, especially when the structure has not performed to expectations. Knowledge of the slag/binder ratio and the water/binder ratio also greatly assists in predicting the residual life of concrete structures exposed to environments chemically aggressive to reinforced concrete such as marine environments. Therefore, there is a need for a reliable and rapid method for estimating the slag content and w/b ratio in concrete. However, once concrete has hardened, it is often very difficult to determine the exact amounts of cement, slag and water that were added during batching.

Existing methods for determining the slag content in hardened concrete are reviewed in Table 1. Although several methods have been used, there is no widely accepted standard method nor is there agreement as to which is best. Testing of slag content in hardened concrete is known to be prone to errors. All of the prevailing methods require either the chemical composition of the original cement and slag used in the tested concrete to be known, or comparison with reference standards made with similar materials, mix proportions and curing conditions as the sample in question. In practice, the original materials that were used may be unknown or no longer available at the time of the investigation. Very often, it is the slag content by mass of total cementitious materials (s/b) that was specified and it is this that is more important with regard to concrete properties including most durability-related properties. If the test method determines the slag content by weight of concrete, this must be converted to slag content by mass of total cementitious 


\begin{tabular}{|c|c|c|}
\hline Method & Description & Accuracy/precision \\
\hline $\begin{array}{l}\text { Sulphide content } \\
\text { [BS 1881: Pt } \\
\text { 124:1988 [1]] }\end{array}$ & $\begin{array}{l}\text { Slag is usually the only ingredient in concrete containing a significant } \\
\text { amount of sulphide. Thus, the amount of slag in concrete can be } \\
\text { estimated from its sulphide content provided the composition of the } \\
\text { slag is known. However, not all sulphide is recovered so the slag } \\
\text { content may be underestimated. The amount of soluble silica and } \\
\text { calcium oxide originating from the slag or aggregates is required to } \\
\text { determine cement content. Aggregates may contain sulphide and this } \\
\text { must be taken into account. }\end{array}$ & $\begin{array}{l}\text { No published precision data is } \\
\text { available. A repeatability of } 15- \\
20 \% \text { has been suggested based on } \\
\text { experience [2]. Sangha et al. [3] } \\
\text { found errors of } 8-27 \% \text { in the slag } \\
\text { content for w/b } 0.5 \text { pastes } \\
\text { containing } 20-80 \% \text { slag cured up to } \\
56 \text { days. }\end{array}$ \\
\hline $\begin{array}{l}\text { Energy-dispersive } \\
\text { X-ray spectroscopy } \\
\text { (EDS) [4-6] }\end{array}$ & $\begin{array}{l}\text { The oxide compositions of the unreacted slag, unreacted cement and } \\
\text { hydrated cement paste in the unknown sample are measured by SEM- } \\
\text { EDS spot analyses. Similar measurements are carried out on reference } \\
\text { standards containing known slag amounts. The s/b ratio is then } \\
\text { estimated from the ternary plot of } \mathrm{MgO}, \mathrm{Al}_{2} \mathrm{O}_{3} \text { and } \mathrm{CaO} \text {, or from the } \\
\text { plot of the ratio }\left(\mathrm{MgO}+\mathrm{Al}_{2} \mathrm{O}_{3}\right) \text { to binder and slag. }\end{array}$ & $\begin{array}{l}\text { Precision based on repeated } \\
\text { analyses of standards has been } \\
\text { found to be } \sim 2 \% \text { at a slag } \\
\text { replacement level of } 25 \% \text { [5]. }\end{array}$ \\
\hline $\begin{array}{l}\text { X-ray diffraction } \\
\text { [7] }\end{array}$ & $\begin{array}{l}\text { The sample is ignited at } 950-1050^{\circ} \mathrm{C} \text { to devitrify the unreacted slag, } \\
\text { then mixed with } 10 \% \mathrm{CaF}_{2} \text { (as internal standard) and analysed by } \\
\mathrm{XRD} \text {. To estimate slag content, the melilite/CaF } \mathrm{C}_{2} \text { peak intensity ratio is } \\
\text { measured and compared to those from mixtures of ignited slag from the } \\
\text { same source as calibration. Note that only the unreacted slag fraction is } \\
\text { measured and significant errors could occur if aggregates are not } \\
\text { properly separated from the paste. }\end{array}$ & $\begin{array}{l}\text { Hooton and Rogers [7] tested ten } \\
\text { mortars with } 0-90 \% \text { slag that were } \\
\text { cured for } 28 \text { days and found that } \\
\text { the slag content could be estimated } \\
\text { to } \sim 10 \% \text { of the actual value when } \\
\text { the data are properly calibrated. }\end{array}$ \\
\hline $\begin{array}{l}\text { X-ray fluorescence } \\
\text { [8] }\end{array}$ & $\begin{array}{l}\text { Oxide compositions of the unknown concrete and reference cement, } \\
\text { slag and aggregates are obtained by XRF. The mix proportions of the } \\
\text { concrete are then determined by considering mass balance and solving } \\
\text { a set of linear equations. Sisomphon [9] showed a variation of this } \\
\text { approach based on the amount of CaO in the hardened paste, reference } \\
\text { cement and slag. However, accuracy would be affected if aggregates } \\
\text { are not properly removed from the paste. The method is not suitable for } \\
\text { concretes containing calcareous aggregates. }\end{array}$ & $\begin{array}{l}\text { Sisomphon [9] tested three } \\
\text { concretes with } 0.45 \mathrm{w} / \mathrm{b} \text { ratio, } 30- \\
70 \% \text { slag cured for up to } 91 \text { days. } \\
\text { Slag content was estimated with an } \\
\text { accuracy of } \sim 6 \% \text {. }\end{array}$ \\
\hline $\begin{array}{l}\text { Electrical } \\
\text { conductivity } \\
{[10]}\end{array}$ & $\begin{array}{l}\text { Xie et al. [10] found an empirical relationship between the electrical } \\
\text { conductivity of concrete, aggregate fraction and s/b ratio that may be } \\
\text { used to determine slag content in unknown mixtures. However, the } \\
\text { relationship would be dependent on other factors that influence } \\
\text { conductivity, especially w/b ratio, degree of hydration and degree of } \\
\text { saturation. }\end{array}$ & Unknown \\
\hline $\begin{array}{l}\text { Optical microscopy } \\
{[7,11]}\end{array}$ & $\begin{array}{l}\text { A polished thin-section is prepared and observed using polarised light } \\
\text { microscopy. The amount of slag as a proportion of the paste is } \\
\text { measured by point-counting and compared to a set of reference thin- } \\
\text { sections to estimate slag content. However, only particles larger than } \\
\text { the thickness of the thin section }(25 \mu \mathrm{m}) \text { can be detected. Smaller } \\
\text { particles can be obscured by overlying hydrates [5]. }\end{array}$ & $\begin{array}{l}\text { McIver \& Davis [11] found } \\
\text { estimates were within } 10-20 \% \text { for } \\
\text { samples with } 0-90 \% \text { slag. When } \\
\text { properly calibrated, the estimated } \\
\text { slag content was } \sim 10 \% \text { of the } \\
\text { actual value [7]. }\end{array}$ \\
\hline
\end{tabular}


1999 [14] describes a method for estimating w/c ratio using fluorescence microscopy. This method requires comparison to a set of suitable reference thin-sections, which should be made with the same ingredients, mix proportions and degree of hydration, as the concrete being examined [12, 13, 15]. A method based on image analysis of backscattered electron micrographs for estimating the original w/c ratio of hardened pastes [16], mortars and concretes [17] that does not require reference standards has been proposed by two of the authors of this paper. However, it is not known if this method is applicable to systems containing slag.

In this paper, a new method for estimating the composition of hardened slag-blended concretes, with the potential to overcome the drawbacks of existing methods, is presented. The method involves measuring the volume fractions of reacted slag, unreacted slag, unreacted cement and air voids by means of image analysis, and measuring the evaporable and non-evaporable water contents based on the mass loss of saturated surface dry samples upon heating and ignition. The results are then used to determine the initial slag, cement and water contents of the cement paste, thus permitting both the w/b and s/b ratios to be calculated. In addition, the method can estimate the degrees of hydration of both cement and slag. Results obtained from slag-blended cement pastes with a wide range of mix compositions and curing ages are presented.

\section{Proposed method}

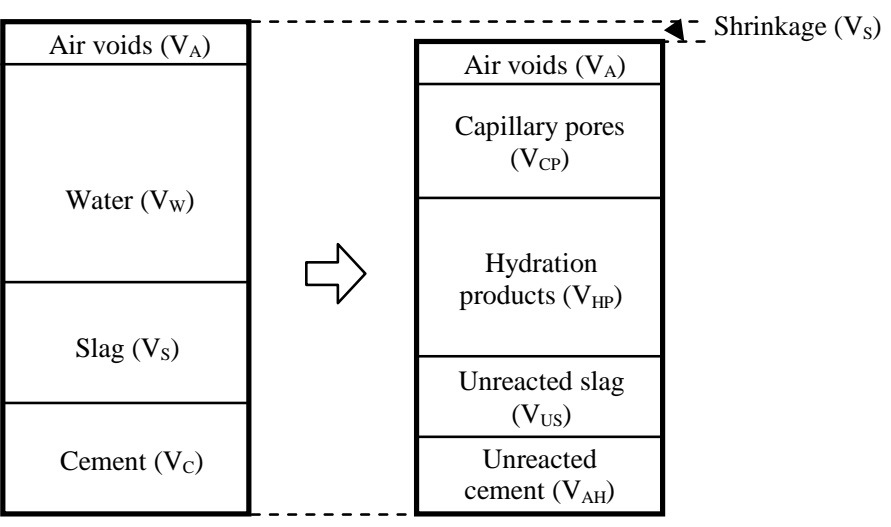

(a) At time of initial set

(b) At time $t$ after initial set

Figure 1: Main constituents in the paste fraction of hardened slag-blended concrete at (a) time of initial set and (b) at time $t$ after initial set. (Not to scale) 
Fig. 1 shows a schematic representation of the volumetric proportions of the main constituents in hardened slag-blended cement paste. At any moment after setting, the hardened cement paste can be thought to consist of: i) the remaining unreacted cement, ii) unreacted slag, iii) hydration products, iv) capillary pores and v) air voids (entrapped or entrained). The sum of their volume fractions and any shrinkage must be equal to the sum of volume fractions of the original cement, slag, free water and air voids at the time of set. Hydration products are expected to occupy the original (time of initial set) water-filled space, thus the volume of air voids is expected to remain unchanged with time.

Assuming that the total shrinkage is small and negligible for the purpose of this study (See Discussion):

$$
V_{C}+V_{S}+V_{W}+V_{A}=V_{A H}+V_{U S}+V_{C P}+V_{A}=1
$$

The volume fraction of cement, $V_{S}$ can be expressed in terms of the volume fractions of slag $V_{S}$, water $V_{W}$ and air voids $V_{A}$ as:

$$
V_{C}=1-\left(V_{S}+V_{W}+V_{A}\right)
$$

The volume fractions of slag, $V_{S}$ (= unreacted, $V_{U S}+$ reacted, $V_{R S}$ ) and air voids, $V_{A}$ can be measured directly using backscattered electron microscopy and image analysis (see Section 3.3 for detailed description). The water content, $V_{W}$ can be estimated from loss on heating and ignition from a saturated and surface dry condition as described in Section 3.4 or alternatively by means of thermal gravimetric analysis (TGA). If the specific gravities of cement, slag and water are $\rho_{\mathrm{c}}, \rho_{\mathrm{s}}$ and $\rho_{\mathrm{w}}$, respectively, the water-binder $(w / b)$ ratio and the slag-binder $(s / b)$ ratio can be calculated using Eq. (3) and Eq. (4) respectively:

$$
\begin{aligned}
& \frac{w}{b}=\frac{V_{W} \rho_{W}}{V_{s} \rho_{s}+V_{C} \rho_{C}}=\frac{V_{W} \rho_{W}}{V_{s} \rho_{s}+\left[1-\left(V_{S}+V_{W}+V_{A}\right)\right] \rho_{C}} \\
& \frac{s}{b}=\frac{V_{S} \rho_{S}}{V_{s} \rho_{s}+V_{C} \rho_{C}}=\frac{V_{S} \rho_{S}}{V_{s} \rho_{s}+\left[1-\left(V_{S}+V_{W}+V_{A}\right)\right] \rho_{C}}
\end{aligned}
$$

To summarise, the proposed method uses backscattered electron microscopy and image analysis to measure the volume fractions of unreacted slag $V_{U S}$, reacted slag $V_{R S}$, and air voids $V_{A}$. The original slag fraction $V_{S}$ is then estimated from the sum of $V_{U S}$ and $V_{R S}$. The original water content $V_{W}$ is estimated by measuring the evaporable and non-evaporable water content. The original cement fraction $V_{C}$ can then be calculated from $V_{S}, V_{W}$ and $V_{A}$ using Eq. (2), thus allowing the w/b and s/b ratios to be calculated using Eq. (3) and Eq. (4) respectively. The degree of reaction of slag $\left(m_{S}\right)$ can be calculated as the ratio of the reacted slag to its initial volume fraction: 


$$
m_{S}=\frac{V_{R S}}{V_{S}}
$$

Similarly, by measuring the volume fraction of unreacted cement, $V_{A H}$ using backscattered electron microscopy, the degree of hydration of cement $\left(m_{c}\right)$ can be calculated from:

$$
m_{C}=1-\frac{V_{A H}}{V_{C}}=1-\frac{V_{A H}}{1-\left(V_{S}+V_{W}+V_{A}\right)}
$$

\section{Experimental}

\subsection{Materials and sample preparation}

Twenty slag-blended cement pastes with water/binder ratios in the range of 0.30 to 0.50 and slag contents of $0,20 \%$, $40 \%$ and $60 \%$ by mass of the total cementitious materials were prepared (Table 2). For each mix, three samples were prepared, giving a total of sixty samples. The composition of the CEM I cement, obtained from XRD-Rietveld analysis, is $64.5 \%$ alite, $16.2 \%$ belite, $6.7 \%$ aluminate and $8.7 \%$ ferrite. The oxides composition of the slag, obtained from XRF analysis, is $36.5 \% \mathrm{SiO}_{2}, 11.6 \% \mathrm{Al}_{2} \mathrm{O}_{3}, 1.4 \% \mathrm{Fe}_{2} \mathrm{O}_{3}, 40.8 \% \mathrm{CaO}, 7.5 \% \mathrm{MgO}, 2.1 \% \mathrm{SO}_{3}$ and $0.5 \% \mathrm{Na}_{2} \mathrm{O}_{\text {equiv. }}$ It is noted that the sulphur content in slag exists mainly in the form of sulphide, but it is measured as $\mathrm{SO}_{3}$ by $\mathrm{XRF}$. The loss-onignition at $1000^{\circ} \mathrm{C}$ for the cement and slag were $2.98 \%$ and $-0.99 \%$ respectively. The negative value of LOI for slag was due to the oxidation of the sulphide content in slag during ignition [18].The specific gravities of the slag and cement were 2.9 and 3.15 respectively.

The raw materials were mixed with tap water in a bowl mixer and compacted in three equal layers into plastic cylindrical moulds (49 mm diameter, $58 \mathrm{~mm}$ height) using a vibrating table with adjustable intensity. Samples were capped and sealed with tape, taking care to prevent any entrapped air and leakage. Subsequently, they were slowly rotated for $24 \mathrm{~h}$ to avoid bleeding and segregation effects. One sample from each mix was left to cure in its mould at room temperature for 3 days whilst the remaining samples were de-moulded and placed in a curing chamber at $100 \%$ $\mathrm{RH}, 20^{\circ} \mathrm{C}$ until the ages of 28 days and 1 year. 
159

160

161

162

163

164

165

166

167

168

169

170

At the end of each designated curing period, a rectangular block sample $(45 \times 20 \times 8 \mathrm{~mm})$ was cut from the centre of each cylinder using a diamond saw. The blocks together with the off-cuts were oven-dried at $40^{\circ} \mathrm{C}$ until constant mass in order to facilitate the penetration and polymerisation of epoxy resin. After that, the blocks were encased and impregnated with low viscosity epoxy, which protects the microstructure from damage during preparation and provides contrast for backscattered electron imaging. The epoxy was pre-heated to $50^{\circ} \mathrm{C}$ and thinned with toluene. A 2.5 bar pressure was further applied on the impregnated sample to ensure deep penetration [19]. The epoxy-impregnated blocks were cured for several days at room temperature to allow sufficient hardening of the resin. Following that, the blocks were ground and polished with diamonds at successively finer grades to $0.25 \mu \mathrm{m}$.

Table 2: Mix proportions of the slag-blended cement pastes

\begin{tabular}{llccccc}
\hline No & Designation & Cement (g) & Slag (g) & Water $(\mathbf{g})$ & w/b & Slag (\% mass) \\
\hline 1 & P 0.3 & 1000 & 0 & 300 & 0.30 & 0 \\
2 & P 0.3-20 & 800 & 200 & 300 & 0.30 & 20 \\
3 & P 0.3-40 & 600 & 400 & 300 & 0.30 & 40 \\
4 & P 0.3-60 & 400 & 600 & 300 & 0.30 & 60 \\
\hline 5 & P 0.35 & 1000 & 0 & 350 & 0.35 & 0 \\
6 & P 0.35-20 & 800 & 200 & 350 & 0.35 & 20 \\
7 & P 0.35-40 & 600 & 400 & 350 & 0.35 & 40 \\
8 & P 0.35-60 & 400 & 600 & 350 & 0.35 & 60 \\
\hline 9 & P 0.4 & 1000 & 0 & 400 & 0.40 & 0 \\
10 & P 0.4-20 & 800 & 200 & 400 & 0.40 & 20 \\
11 & P 0.4-40 & 600 & 400 & 400 & 0.40 & 40 \\
12 & P 0.4-60 & 400 & 600 & 400 & 0.40 & 60 \\
\hline 13 & P 0.45 & 1000 & 0 & 450 & 0.45 & 0 \\
14 & P 0.45-20 & 800 & 200 & 450 & 0.45 & 20 \\
15 & P 0.45-40 & 600 & 400 & 450 & 0.45 & 40 \\
16 & P 0.45-60 & 400 & 600 & 450 & 0.45 & 60 \\
\hline 17 & P 0.5 & 1000 & 0 & 500 & 0.50 & 0 \\
18 & P 0.5-20 & 800 & 200 & 500 & 0.50 & 20 \\
19 & P 0.5-40 & 600 & 400 & 500 & 0.50 & 40 \\
20 & P 0.5-60 & 400 & 600 & 500 & 0.50 & 60 \\
\hline
\end{tabular}

In addition to the paste samples, four epoxy mixes containing dry cement and slag were prepared at epoxy/binder (e/b) mass ratio of 0.5 . Their proportions are shown in Table 3. These were prepared to validate the point-counting procedure (Section 3.3) on samples containing only unreacted cement and slag particles. No hydration would occur since water was absent. The epoxy mixes were prepared by first dry mixing the required amount of cement and slag in a cup. Epoxy was then added and stirred rigorously until a uniform mix was obtained. The cup was then placed in a vacuum chamber for 30 minutes to remove all entrapped air. Subsequently, a hardener was added and the mixture was stirred again, 
before being placed into the vacuum chamber for a further 30 minutes. The mixture was left to harden at room temperature for approximately 48 hours. It was unnecessary to continuously rotate the epoxy mixed during hardening since segregation is not expected to be significant in a viscous resin. Then a rectangular block $(45 \times 20 \times 8 \mathrm{~mm})$ was extracted by taking a vertical slice from the centre of the cylinder, then ground and polished in the manner described above.

Table 3: Proportions of the epoxy mixes containing cement and slag

\begin{tabular}{llccccc}
\hline No & Designation & Cement (g) & Slag (g) & Epoxy + hardener (g) & e/b & Slag (\% mass) \\
\hline 1 & E 0.5 & 120 & 0 & 60 & 0.50 & 0 \\
2 & E $0.5-20$ & 96 & 24 & 60 & 0.50 & 20 \\
3 & E 0.5-40 & 72 & 48 & 60 & 0.50 & 40 \\
4 & E 0.5-60 & 48 & 72 & 60 & 0.50 & 60 \\
\hline
\end{tabular}

\subsection{SEM-BSE imaging}

A Camscan Apollo 300 field-emission SEM was used for imaging. The SEM was operated in high-vacuum, at $10 \mathrm{kV}$ accelerating voltage and working distance of between 10 to $15 \mathrm{~mm}$. Samples were viewed at 500× magnification, which gives a field of view of $240 \times 192 \mu \mathrm{m}$ per frame. Each frame was digitised to $2560 \times 2048$ pixels with a pixel spacing of $0.094 \mu \mathrm{m}$. This represents a good compromise for obtaining a decent sampling area and high resolution to discriminate the phases of interest. The brightness and contrast settings were adjusted so that the contrast between the unreacted cement, unreacted slag, reacted slag and voids were optimised to facilitate the identification of different phases in the samples. The same setting was applied for all frames to ensure consistency. To avoid charging artefacts, the polished samples were pre-coated with a thin layer $(\sim 50 \mathrm{~nm})$ of carbon using an evaporative coater.

\subsection{Image analysis}

The brightness of each pixel in a BSE image increases monotonically with mean atomic number of the underlying phase. For a typical slag-blended paste, the unreacted cement will appear brightest, followed by the unreacted slag, portlandite, C-S-H, reacted slag and epoxy-filled pores and cracks (Fig. 2). Since some phases share similar mean atomic numbers (e.g. unreacted slag and portlandite), pixel brightness alone may not be sufficient to differentiate all 
phases. Furthermore, using Monte-Carlo simulations, we found that the sampling depth and escape surface radius of backscattered electrons in cement-based materials can be up to 0.5 and $1.5 \mu \mathrm{m}$ respectively at $10 \mathrm{kV}$ accelerating voltage [20] so pixels that sample more than one phase will show averaged intensities. These make phase segmentation on the basis of greyscale alone difficult. Greyscale segmentation can be combined with information from element maps obtained using energy-dispersive X-ray spectroscopy (EDS) [21, 22]. However, this could be a time consuming procedure if many frames are required.

Hence, point counting analysis, which will be further described below, was adopted to measure the volume fractions of unreacted slag, reacted slag, unreacted cement, air voids and limestone filler in the samples. Pixel brightness along with visual information such as particle size, shape and texture was used for identifying the phases. This is subjective and could introduce a source of error. Hence where necessary, the elemental composition was determined via spot analysis using EDS to confirm the phase present. For example, slag grains are angular, appear smooth and have sharply defined boundaries (Fig. 2a). In well hydrated samples, dark rims that indicate the extent of slag reaction are clearly visible. An EDS spot analysis on the slag reaction rims shows that they contain similar elements to the unreacted slag, but significantly reduced Ca and Si peaks. The Mg peak remains virtually unchanged due to the low mobility of Mg and does not significantly migrate from the original slag grain [23-25]. As hydration proceeds, the width of the slag reaction rim increases (Fig. 2b). Small slag particles may appear as fully reacted relicts, hence darker in colour, but their angular shape and original boundary remain visible. These characteristics allow good discrimination between reacted and unreacted slag, particularly at later ages. It should also be noted that what appear as small slag particles in the BSE image may actually be sectioned tips of larger particles.

\section{The point counting analysis was performed by superimposing a 99-point grid on each live image and the phase} intersected at every grid point was identified by a trained operator and tallied using a counting device. However, a grid point may fall on the boundary of different phases and this might cause ambiguities. In such cases, the phase that lies on the upper right corner of the grid point was recorded to ensure a systematic and unambiguous point counting procedure. This process was repeated for 30 frames taken at random locations spanning the sample to obtain a representative average. Assuming that the counted phases are randomly distributed in the microstructure, the total number of points that fall on a particular phase divided by the total number of points counted (2970) provides an unbiased estimate of the volume fraction of that phase (i.e. volume fraction of a phase = number of points falling on that phase $/$ total number of 
points counted). The time required by a trained operator to complete a point count analysis on each sample was

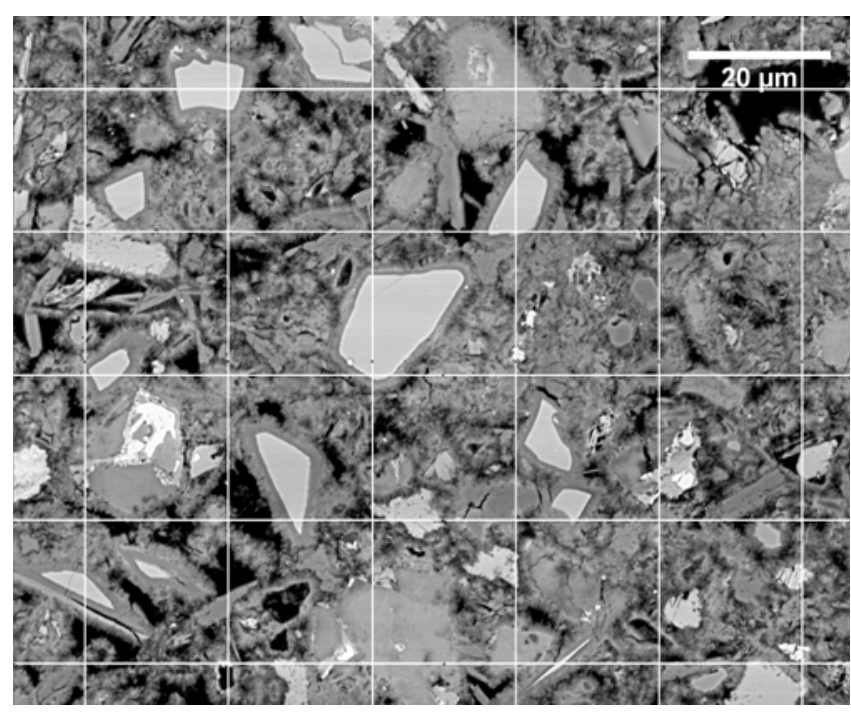

(a) P $0.5-20$ at 28 days

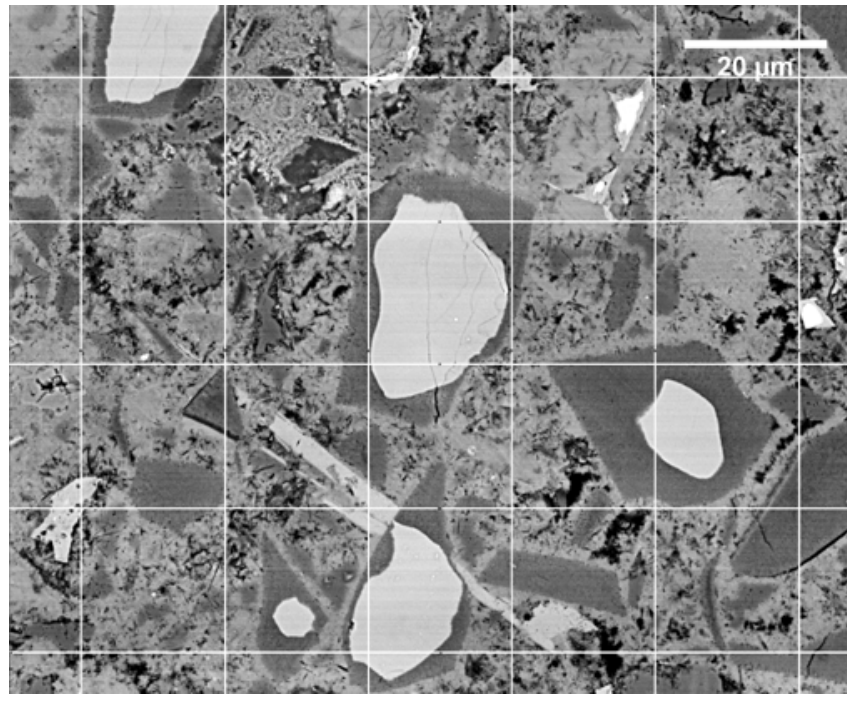

(b) P 0.5-20 at 1 year

Figure 2: BSE images of cement pastes at w/b ratio of 0.5 containing $20 \%$ slag replacement after curing for (a) 28 days and (b) 1 year. A grid is superimposed on the images for point-counting. Field of view is $120 \times 96 \mu \mathrm{m}$.

Fig. 3 shows plots of moving averages for the measured volume fractions of (a) slag (reacted + unreacted) and (b) unreacted cement against number of frames analysed for pastes at $0.45 \mathrm{w} / \mathrm{b}$ ratio containing 20,40 \& $60 \%$ slag at ages of 3 days and 1 year. The results show that as the number of frames analysed increases, the cumulative average converges to a relative stable value suggesting that the cumulative average after 30 frames is representative and that analysing more frames would not significantly alter the results. 


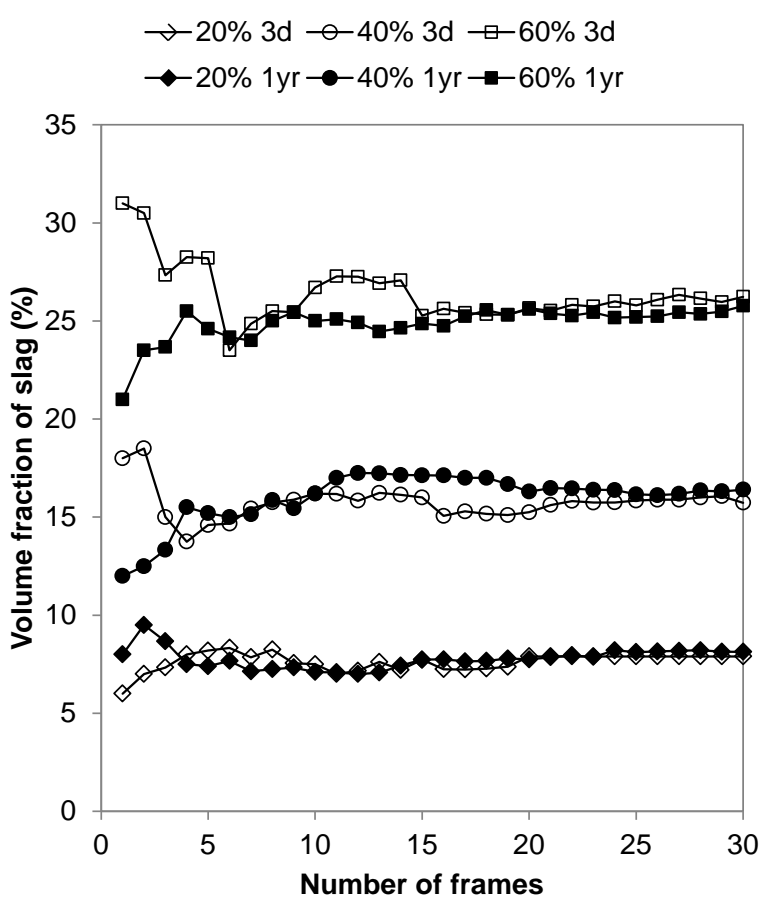

(a)



(b)

Figure 3: Plot of moving average of the measured volume fractions of (a) slag and (b) unreacted cement against number of image frames. Samples are pastes at $0.45 \mathrm{w} / \mathrm{b}$ ratio containing $20,40 \& 60 \%$ slag at an age of 3 days and 1 year.

\subsection{Water content}

The original water content was estimated by measuring the sum of the evaporable and non-evaporable water in the offcuts from each mix. The off-cuts measuring about $49 \mathrm{~mm}$ in diameter and $25 \mathrm{~mm}$ in height were placed in cups, deaired in a vacuum chamber and then immersed in de-aired water without breaking the vacuum. The vacuum is subsequently released and an additional 2.5 bars above atmospheric pressure is applied and maintained for about 30 minutes. The saturated off-cuts were then surface-dried and weighed. To avoid any errors potentially caused by water absorbed into large air voids during vacuum saturation, the off-cuts were crushed into small pieces and reweighed. This proved to be unnecessary as no significant amount of air voids were found and reweighing the crushed off-cuts did not detect any mass difference. The volume of the off-cuts $V_{o}$ was measured by applying Archimedes's principle by lowering the off-cut into a water-filled beaker until fully submerged and measuring the mass change.

Following that, the off-cuts were placed in a crucible and dried at $105^{\circ} \mathrm{C}$ until constant mass. The mass difference between the saturated surface-dried and oven-dried $\left(105^{\circ} \mathrm{C}\right)$ condition was taken as the mass of evaporable water $\left(m_{e}\right)$. 
The off-cuts were then placed into a furnace and ignited at $1000^{\circ} \mathrm{C}$ for $4 \mathrm{~h}$. The drying and ignition processes were carried out in $\mathrm{CO}_{2}$-free conditions. The mass difference between the oven-dried $\left(m_{105}\right)$ and ignited condition $\left(m_{1000}\right)$, corrected for any mass change of the unreacted cement and slag, was taken as the mass of non-evaporable water $\left(m_{n}\right)$. Weighing was carried out in an analytical balance with precision of $0.0001 \mathrm{~g}$.

$$
m_{n}=m_{105}-m_{1000}+\left(V_{A H} \rho_{c} L O I_{C}+V_{U S} \rho_{S} L O I_{S}\right) V_{0}
$$

Where $L O I_{C}$ and $L O I_{S}$ are the loss on ignition of cement and slag respectively, and $V_{A H}$ and $V_{U S}$ are estimated from point counting, and $V_{o}$ is the volume of the off-cut. Having determined the masses of evaporable and non-evaporable water, the volume fraction of water is calculated as:

$$
V_{W}=\frac{m_{e} v_{e}+m_{n} v_{n}}{V_{0}}
$$

Where $v_{e}\left(1.0 \mathrm{~cm}^{3} / \mathrm{g}\right)$ and $v_{n}\left(0.72 \mathrm{~cm}^{3} / \mathrm{g}\right)$ are the specific volumes of the evaporable and non-evaporable water respectively. We assume that the specific volume of evaporable water is equal to that of free water (i.e. $1.0 \mathrm{~cm}^{3} / \mathrm{g}$ ). In fact, a portion of the evaporable water is water held within the intrinsic gel pores of the hydration products, which may have a specific volume of slightly lower than $1.0 \mathrm{~cm}^{3} / \mathrm{g}$ [26].

The specific volume of non-evaporable water $v_{n}\left(=0.72 \mathrm{~cm}^{3} / \mathrm{g}\right)$ is based on the work of Powers and Brownyard [27] because of lack of a better value for slag-blended systems. Here, we have inevitably assumed that $v_{n}$ does not depend on the binder composition and degree of reaction, and that the physical properties of hydration products of slag-blended cement pastes are similar to those in Portland cement pastes. This is an approximation since it is well-established that the clinker phases hydrate at different rates to form different amounts of hydrates (mainly C-S-H, portlandite, ettringite and AFm phases) containing different amounts of water. Nevertheless, it is often observed that the amount of chemically-bound water per mass of reacted material is similar for Portland cements. However, the presence of slag changes the reactivity of the clinker phases, hydration kinetics, the type and amount of the hydrates formed [28-30]. 


\section{Results}

\subsection{Epoxy mixes}

As mentioned in Section 3.1, four epoxy mixes containing dry cement and slag at 20\%, 40\% and 60\% replacement, and epoxy/binder mass ratio of 0.5 were prepared to test and validate the point counting procedure. The volume fractions of the cement, slag and epoxy were measured by point-counting and the results were converted to mass fractions based on known densities of the raw materials. The density of epoxy was taken as $1.1 \mathrm{~g} / \mathrm{cm}^{3}$. The measured mass fractions and slag/binder (i.e. slag/(slag + binder)) ratio are compared against the theoretical values in Fig. 4. The results demonstrate that the point count measurements were indeed very accurate for the non-hydrated samples. The mean absolute errors for mass fractions of cement and slag, and slag/binder ratio were $2.48 \%$, 3.74\% and 2.92\%, respectively. Absolute error is calculated as the absolute difference between the measured and actual value, expressed as a percentage of the actual value. Hereafter, mean absolute error refers to the averaged absolute errors for each constituent. No visible sign of segregation of cement and slag was observed in the cross-section of the epoxy mixes.

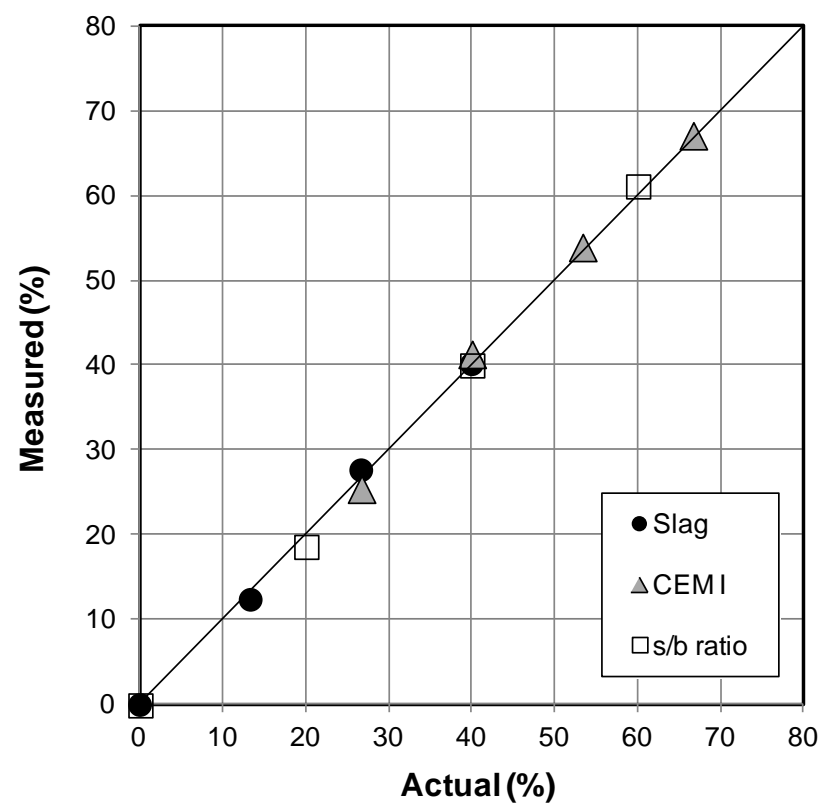

Figure 4: Comparison between actual and measured mass fractions of slag, cement and slag/binder ratio in epoxy mixes 


\subsection{Cement pastes}

Table 4 presents the measured volume fractions of unreacted slag, reacted slag and unreacted cement (from pointcounting) and water (sum of evaporable and non-evaporable water) for all samples. The measured volume fractions of air voids and limestone filler were insignificant and typically less than $0.1 \%$, thus are not shown. The results indicate that the amount of unreacted slag and unreacted cement decreases with curing age, while the amount of reacted slag increases with curing age, as expected. The sum of reacted and unreacted slag is relatively constant with curing age. These trends are consistent throughout the dataset.

Table 4: Measured volume fractions (\%) of unreacted slag, reacted slag, unreacted cement and water for all samples.

\begin{tabular}{|c|c|c|c|c|c|c|c|c|c|c|c|c|}
\hline \multirow{2}{*}{ Sample } & \multicolumn{3}{|c|}{ Unreacted slag $\left(V_{U S}\right)$} & \multicolumn{3}{|c|}{ Reacted slag $\left(V_{R S}\right)$} & \multicolumn{3}{|c|}{ Unreacted cement $\left(V_{A H}\right)$} & \multicolumn{3}{|c|}{ Water $\left(V_{W}\right)$} \\
\hline & 3d & 28d & $1 \mathrm{yr}$ & 3d & 28d & $1 \mathrm{yr}$ & 3d & 28d & $1 y r$ & 3d & 28d & $1 y r$ \\
\hline P 0.3 & 0.0 & 0.0 & 0.0 & 0.0 & 0.0 & 0.0 & 23.7 & 20.4 & 11.9 & 46.9 & 50.6 & 49.0 \\
\hline P 0.3-20 & 9.9 & 7.6 & 5.0 & 0.8 & 1.9 & 6.1 & 16.7 & 14.1 & 8.4 & 48.8 & 48.3 & 49.8 \\
\hline P 0.3-40 & 20.0 & 15.5 & 11.8 & 1.0 & 2.1 & 8.5 & 11.8 & 10.7 & 7.5 & 45.9 & 47.8 & 49.9 \\
\hline P 0.3-60 & 27.6 & 22.2 & 18.5 & 0.8 & 2.6 & 10.6 & 7.3 & 5.9 & 4.9 & 46.7 & 48.6 & 49.7 \\
\hline P 0.35 & 0.0 & 0.0 & 0.0 & 0.0 & 0.0 & 0.0 & 23.6 & 15.4 & 9.1 & 51.5 & 52.8 & 52.6 \\
\hline P 0.35-20 & 7.7 & 6.2 & 4.3 & 1.5 & 2.9 & 6.4 & 17.8 & 12.4 & 6.5 & 52.1 & 54.3 & 54.2 \\
\hline P $0.35-40$ & 19.0 & 12.4 & 10.2 & 1.3 & 3.1 & 8.5 & 12.0 & 9.0 & 3.8 & 52.6 & 53.5 & 54.4 \\
\hline P $0.35-60$ & 26.6 & 23.5 & 16.6 & 2.6 & 5.1 & 10.9 & 6.0 & 5.2 & 3.0 & 51.0 & 51.2 & 52.9 \\
\hline P 0.4 & 0.0 & 0.0 & 0.0 & 0.0 & 0.0 & 0.0 & 21.0 & 17.3 & 6.9 & 57.0 & 54.8 & 56.8 \\
\hline P $0.4-20$ & 9.2 & 6.5 & 3.1 & 0.7 & 2.3 & 6.0 & 13.4 & 9.1 & 5.8 & 56.2 & 57.0 & 56.6 \\
\hline P $0.4-40$ & 18.1 & 12.2 & 8.6 & 1.2 & 3.7 & 8.1 & 11.1 & 6.8 & 3.6 & 56.0 & 55.8 & 55.5 \\
\hline P 0.4-60 & 27.2 & 22.0 & 16.2 & 3.2 & 4.3 & 10.2 & 6.6 & 3.6 & 2.8 & 55.2 & 54.2 & 55.1 \\
\hline P 0.45 & 0.0 & 0.0 & 0.0 & 0.0 & 0.0 & 0.0 & 25.0 & 13.1 & 4.3 & 57.2 & 59.4 & 60.7 \\
\hline P $0.45-20$ & 7.0 & 6.2 & 2.2 & 1.0 & 2.2 & 6.0 & 14.9 & 9.4 & 3.6 & 58.0 & 57.6 & 58.3 \\
\hline P $0.45-40$ & 14.8 & 12.2 & 7.0 & 1.1 & 3.9 & 9.6 & 10.3 & 6.1 & 2.6 & 59.0 & 59.3 & 57.0 \\
\hline P $0.45-60$ & 25.1 & 21.7 & 13.7 & 1.4 & 3.4 & 12.4 & 7.5 & 3.0 & 2.1 & 57.7 & 58.5 & 55.8 \\
\hline P 0.5 & 0.0 & 0.0 & 0.0 & 0.0 & 0.0 & 0.0 & 19.7 & 14.0 & 4.3 & 60.9 & 60.4 & 63.3 \\
\hline P $0.5-20$ & 7.0 & 5.5 & 1.3 & 0.3 & 2.1 & 6.5 & 15.2 & 8.8 & 3.0 & 61.9 & 61.4 & 62.1 \\
\hline P $0.5-40$ & 13.0 & 12.0 & 6.1 & 1.3 & 3.9 & 8.8 & 11.6 & 5.8 & 2.5 & 60.9 & 61.7 & 58.9 \\
\hline P 0.5-60 & 19.7 & 20.8 & 12.7 & 2.0 & 4.7 & 9.5 & 8.3 & 2.5 & 1.3 & 61.8 & 57.9 & 59.7 \\
\hline
\end{tabular}

The measured volume fractions of slag, cement (Eq. 2) and water are converted to $\mathrm{kg} / \mathrm{m}^{3}$ and the results are compared against the theoretical values, which can easily be deduced from the known masses of the mix constituents and densities. Fig. 5 plots the experimentally measured against the actual values. The original w/b ratio is then calculated from the slag, cement and water contents, the results are shown in Fig. 6 and Table 5. 

7

The results shown in Fig. 5a suggest that that there is a tendency for the slag content to be slightly underestimated. The mean errors were $-4.3 \%,-11.9 \%$ and $-6.5 \%$ for the 3-day, 28-day and 1-year cured samples, respectively. Here, error is calculated as the difference between the measured and actual value, expressed as a percentage of the actual value. Hereafter, mean error refers to the averaged error for each constituent. We note that the disagreement between measured and actual slag content was somewhat higher for the 28-day cured samples. This is attributable to the outliers in the measurements, for example, two points in Fig. 5a show very large errors of $32.7 \%$ and $24.0 \%$. However, we have not excluded any outliers in the analysis. The reason for the large errors at 28-day is unclear, but probably a result of experimental errors. Nevertheless, considering the large number of samples tested, the results indicate that the point counting method is generally quite accurate in determining the original slag content.

The water content (Fig. 5b) was very well estimated with mean errors of only $0.25 \%, 1.1 \%$ and $1.8 \%$ for the 3-day, 28day and 1-year cured samples, respectively. As for the cement content, the mean errors were $0.1 \%, 5.4 \%$ and $2.2 \%$ at each consecutive curing age. Again, the disagreement between measured and actual cement content was somewhat higher for the 28-day cured samples. This is primarily due to the tendency to underestimate slag content, given the fact that the estimated water content was relatively accurate. The mean absolute errors for all samples were $9.1 \%, 1.5 \%$ and 2.5\% for slag, water and cement content, respectively. 




(a)



(b)

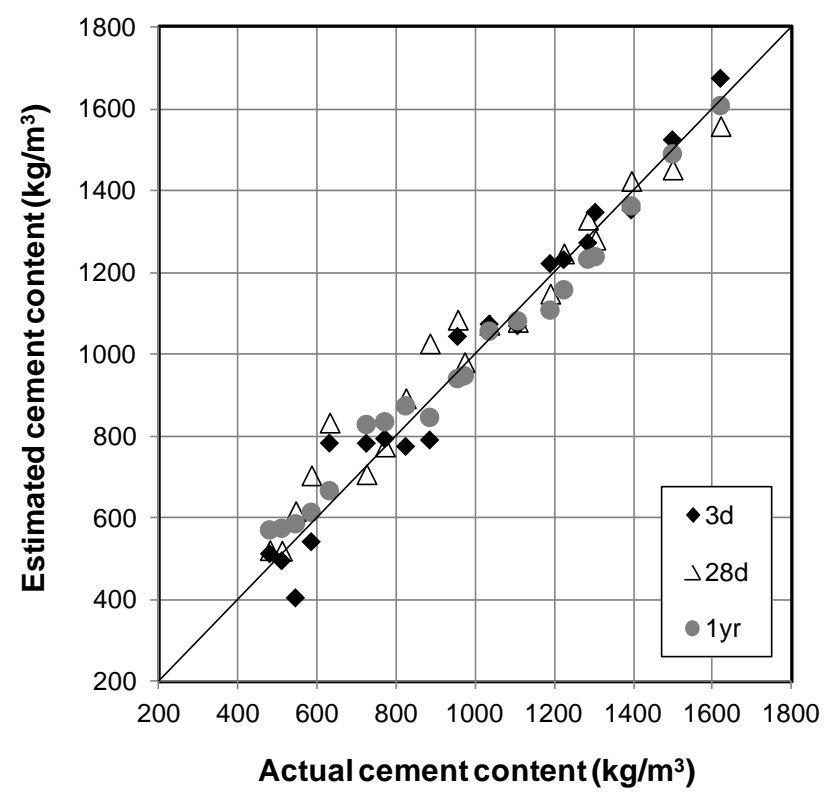

(c)

Figure 5: Comparison between the estimated and actual values of the original (a) slag content, (b) water content and (c) cement content for all samples investigated. Note: results were converted to $\mathrm{kg} / \mathrm{m}^{3}$ by multiplying the measured volume fractions of each material by their respective densities.

A good agreement between the estimated and actual w/b ratios was observed for all samples, regardless of the slag content and curing age. The mean errors of the estimated w/b ratios were $1.2 \%, 2.3 \%$ and 3.8\% for the 3-day, 28-day and 1-year cured samples, respectively. The mean absolute error for all samples was 4.7\%. Of the 60 different samples tested, the largest error in the estimated w/b ratio was only 0.046 . With the exception of 5 samples, all of the estimated 
w/b ratios were within 0.036 of the actual values (Fig. 7). The estimated s/b ratio shown in Table 5 was also reasonably accurate with mean errors of $-2.7 \%,-10.9 \%$ and $-4.9 \%$ for the 3-day, 28-day and 1-year cured samples, respectively. The mean absolute error for s/b ratio for all samples was $8.7 \%$.

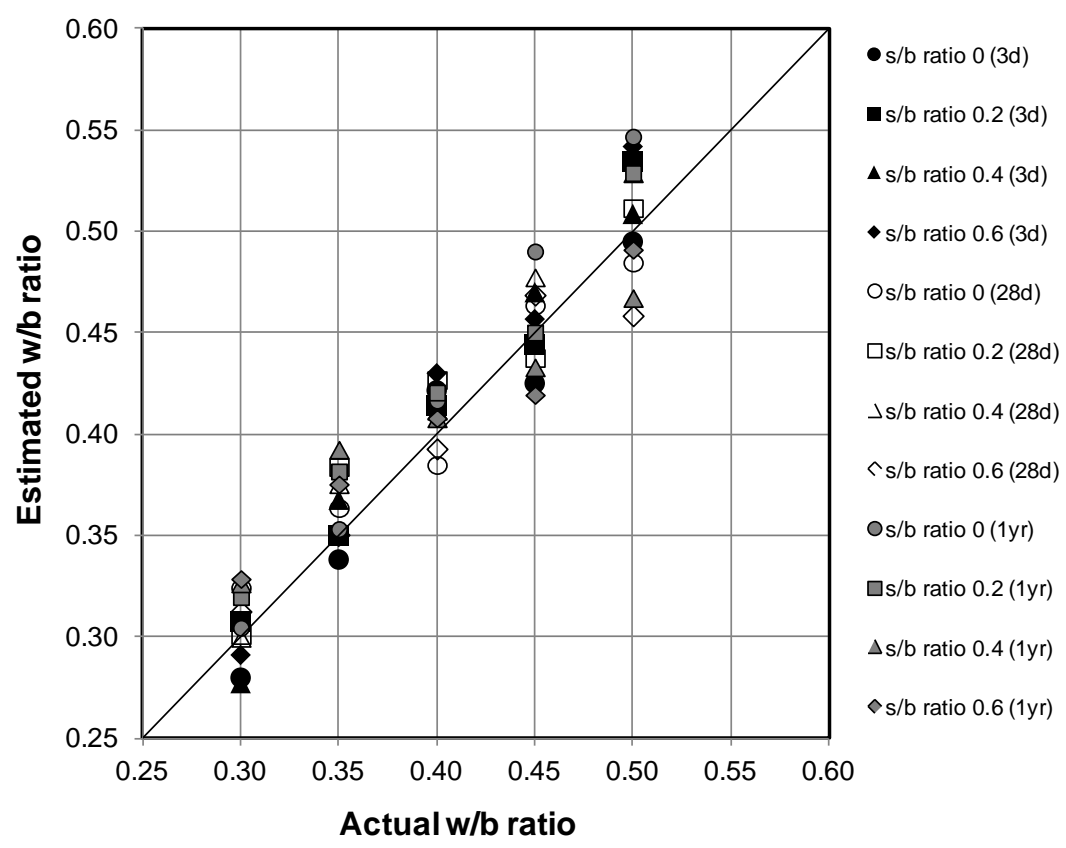

Figure 6: Comparison between the estimated and actual w/b ratio for all samples investigated.



Figure 7: Frequency and cumulative histogram of the absolute error in estimated w/b ratio for all samples. 
Table 5: Measured $w / b$ ratio, $s / b$ ratio and the degrees of reaction of cement $\boldsymbol{m}_{C}$ and slag $\boldsymbol{m}_{S}$

\begin{tabular}{|c|c|c|c|c|c|c|c|c|c|c|c|c|}
\hline \multirow{2}{*}{ Sample } & \multicolumn{3}{|c|}{$\mathbf{w} / \mathbf{b}$} & \multicolumn{3}{|c|}{$\mathbf{s} / \mathbf{b}$} & \multicolumn{3}{|c|}{$\boldsymbol{m}_{C}$} & \multicolumn{3}{|c|}{$m_{S}$} \\
\hline & 3d & 28d & $1 \mathrm{yr}$ & 3d & 28d & $1 \mathrm{yr}$ & 3d & $28 d$ & $1 \mathrm{yr}$ & 3d & 28d & $1 \mathrm{yr}$ \\
\hline P 0.3 & 0.28 & 0.32 & 0.30 & - & - & - & 0.55 & 0.59 & 0.77 & 0.00 & 0.00 & 0.00 \\
\hline P 0.3-20 & 0.31 & 0.30 & 0.32 & 0.20 & 0.17 & 0.21 & 0.59 & 0.66 & 0.79 & 0.08 & 0.20 & 0.55 \\
\hline P 0.3-40 & 0.28 & 0.30 & 0.33 & 0.37 & 0.32 & 0.38 & 0.64 & 0.69 & 0.75 & 0.05 & 0.12 & 0.42 \\
\hline P 0.3-60 & 0.29 & 0.31 & 0.33 & 0.51 & 0.52 & 0.56 & 0.71 & 0.78 & 0.77 & 0.03 & 0.10 & 0.36 \\
\hline P 0.35 & 0.34 & 0.36 & 0.35 & - & - & - & 0.51 & 0.67 & 0.81 & 0.00 & 0.00 & 0.00 \\
\hline P 0.35-20 & 0.35 & 0.38 & 0.38 & 0.18 & 0.19 & 0.22 & 0.54 & 0.66 & 0.81 & 0.16 & 0.32 & 0.59 \\
\hline P 0.35-40 & 0.37 & 0.38 & 0.39 & 0.45 & 0.32 & 0.39 & 0.52 & 0.73 & 0.86 & 0.14 & 0.10 & 0.45 \\
\hline P 0.35-60 & 0.35 & 0.35 & 0.38 & 0.63 & 0.52 & 0.57 & 0.65 & 0.77 & 0.84 & 0.16 & 0.10 & 0.40 \\
\hline Р 0.4 & 0.42 & 0.39 & 0.42 & - & - & - & 0.51 & 0.62 & 0.84 & 0.00 & 0.00 & 0.00 \\
\hline P 0.4-20 & 0.41 & 0.43 & 0.42 & 0.21 & 0.19 & 0.20 & 0.60 & 0.73 & 0.83 & 0.07 & 0.26 & 0.66 \\
\hline P 0.4-40 & 0.42 & 0.41 & 0.41 & 0.42 & 0.34 & 0.36 & 0.55 & 0.76 & 0.87 & 0.06 & 0.23 & 0.49 \\
\hline P 0.4-60 & 0.43 & 0.39 & 0.41 & 0.69 & 0.55 & 0.57 & 0.48 & 0.82 & 0.85 & 0.10 & 0.16 & 0.39 \\
\hline P 0.45 & 0.43 & 0.46 & 0.49 & - & - & - & 0.41 & 0.68 & 0.89 & 0.00 & 0.00 & 0.00 \\
\hline P 0.45-20 & 0.44 & 0.44 & 0.45 & 0.18 & 0.18 & 0.18 & 0.56 & 0.72 & 0.89 & 0.12 & 0.27 & 0.73 \\
\hline P 0.45-40 & 0.47 & 0.48 & 0.43 & 0.37 & 0.38 & 0.37 & 0.59 & 0.75 & 0.90 & 0.07 & 0.24 & 0.58 \\
\hline P 0.45-60 & 0.46 & 0.47 & 0.42 & 0.61 & 0.58 & 0.57 & 0.52 & 0.82 & 0.89 & 0.05 & 0.14 & 0.47 \\
\hline Р 0.5 & 0.50 & 0.49 & 0.55 & - & - & - & 0.49 & 0.65 & 0.88 & 0.00 & 0.00 & 0.00 \\
\hline P $0.5-20$ & 0.54 & 0.51 & 0.53 & 0.18 & 0.18 & 0.19 & 0.49 & 0.72 & 0.90 & 0.04 & 0.28 & 0.83 \\
\hline P $0.5-40$ & 0.51 & 0.53 & 0.47 & 0.35 & 0.39 & 0.34 & 0.53 & 0.74 & 0.90 & 0.09 & 0.25 & 0.59 \\
\hline P 0.5-60 & 0.54 & 0.46 & 0.49 & 0.55 & 0.59 & 0.53 & 0.49 & 0.85 & 0.93 & 0.09 & 0.19 & 0.43 \\
\hline
\end{tabular}

395

396

397

398

399

400

401

402

403

404

405

406

407

408

\subsection{Degree of reaction}

The estimated degrees of reaction of slag (Eq. 5) and cement (Eq. 6) are presented in Table 5. As expected, the degree of reaction of both binders increased with curing age for all samples. The degree of hydration of cement for the 3-day, 28-day and 1-year samples ranged from 0.41 to $0.71,0.59$ to 0.85 and 0.75 to 0.93 , respectively. The presence of slag had a slight accelerating effect on the hydration of cement at 3 and 28 days, but this became insignificant at 1 year. This effect has been reported in previous studies, for example Lumley et al. [31] and Escalante-Garcia \& Sharp [32].

The degree of reaction of slag for the 3-day, 28-day and 1-year samples ranged from 0.03 to $0.16,0.10$ to 0.32 and 0.36 to 0.83 , respectively. The degree of reaction of slag at 28 days and 1 year increased with increasing w/b ratio. At a 
constant $\mathrm{w} / \mathrm{b}$ ratio, the degree of reaction of slag decreased with increasing s/b ratio. These observations are also in agreement with those of Lumley et al. [31] and Escalante et al. [33]. The observed trends can be explained by the dependency of the slag reaction on the amount of available calcium hydroxide and a sustained alkaline-activating environment. Increasing the $\mathrm{w} / \mathrm{b}$ ratio increases the amount of water and space available for the formation of hydration products, thus promoting the hydration of cement and slag. However, these trends were less consistent at 3 days. The reason for this is unclear, but could be due to experimental errors. In young pastes, the reacted slag rims are very narrow and this affects the accuracy of the point-counting.

The estimated degrees of hydration of cement and slag are compared against measured values from conventional image analysis using Eq. (5) and Eq. (6) where the original cement and slag content are known beforehand. Results are displayed in Fig. 8. A good agreement between the estimated and measured values is observed for cement and slag at all curing ages.

It would be interesting to compare the results from this study to those in the literature, but noting that the binders used and their intrinsic reactivity, curing conditions and test methods would not be exactly the same. Feng et al. [34] measured the degree of reaction of slag blended cement pastes with w/b ratio 0.4 and s/b ratio 0.3 using a pointcounting procedure on BSE images. Samples were sealed cured in a $20^{\circ} \mathrm{C}, 100 \% \mathrm{RH}$ environment. The measured degrees of hydration for cement in the blended paste at 3 and 28 days were 0.54 and 0.78 , and for slag were 0.08 and 0.28 respectively. These values seem to agree well with ours for P $0.4-20$ and P $0.4-40$ at s/b ratios of 0.2 and 0.4 (Table 5). The averaged degree of hydration of cement for these two pastes at 3 and 28 days were 0.58 and 0.75 , and for slag were 0.07 and 0.25 , respectively. The good agreement is probably not surprising since that the oxide composition of the slag and the point-counting procedure used by Feng et al. [34] are quite similar to ours. However, it should be noted that our measurements include the reacted slag fraction and the degree of reaction was estimated without requiring prior knowledge of the $\mathrm{w} / \mathrm{b}$ ratio or the original slag and cement contents in the sample.

Our results are also consistent with those of Lumley et al. [31], who carried out an extensive study on the degree of reaction of slag in pastes made with combinations of five cement and seven slag types. The degree of reaction for slag was measured using selective dissolution (EDTA extraction). They observed that for blended pastes at w/b ratio of $0.40-0.60$, s/b ratio of $0.30-0.69$ and sealed cured at $20^{\circ} \mathrm{C}$, about $30-55 \%$ of the slag reacted after 28 days and $38-75 \%$ 
reacted after 1 year. In another study, Kocaba et al. [21] compared five methods for determining the amount of slag

442



a) Cement

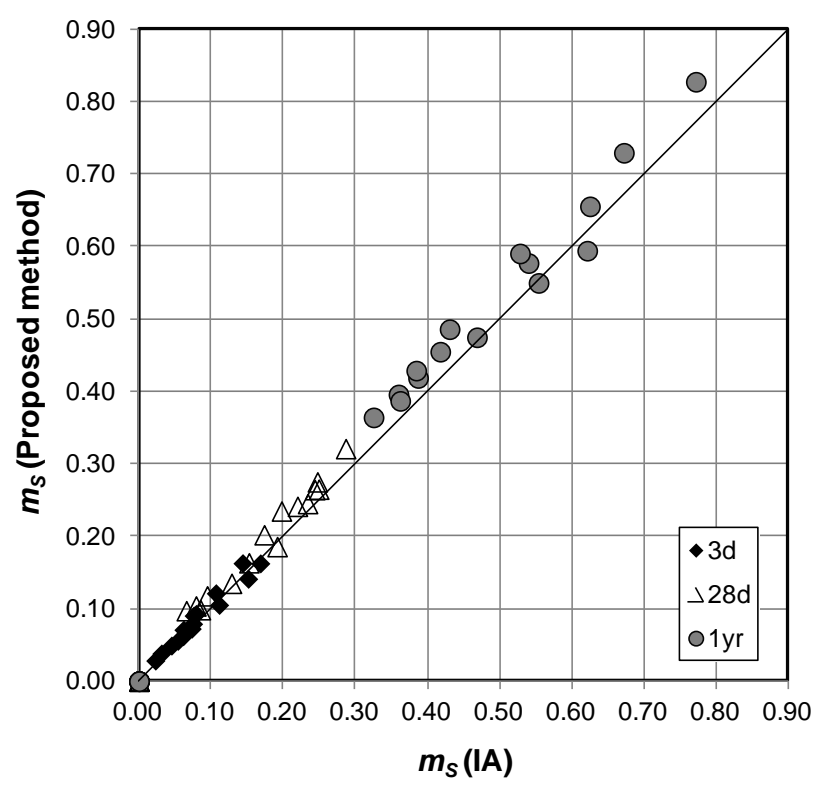

b) Slag reacted in blended systems made with two slag types and three cement types at w/b ratio of 0.42 and s/b ratio of 0.4 . Their results indicated that selective dissolution and differential scanning calorimetry were less reliable compared to methods using BSE image analysis combined with EDS mapping of Mg, isothermal calorimetry or chemical shrinkage. The two slag types studied had very different reactivity. Using the BSE-EDS method, they reported about 10-40\% of the slag reacted after 3 days, 30-55\% reacted after 28 days and 60-75\% reacted after 1 year.

\section{Figure 8: Comparison between the estimated degree of hydration using the proposed method and the measured} degree of hydration from conventional image analysis method

\section{Discussion}

The epoxy mixes containing unreacted cement and slag produced very good results, thus verifying that point counting on backscattered electron images can indeed give accurate estimation of volume fractions. Inevitably, when applied to hydrated cement paste, the observed error increases due to greater complexity in the microstructure of such systems. There are several factors that could contribute to errors and a potential major source lies in counting the reacted slag fraction. This is because the reacted slag shares similar grey level to that of hydration products. In some slag particles, especially at early ages, the reacted slag rims could be too narrow to be accurately identified. This may cause a 
tendency to underestimate the degree of reaction and the total slag content. Small slag particles may be completely reacted, but their angular shape and original boundary remain visible and so the operator must be aware of this.

Because of the finite resolution of the technique, not all of the smallest particles will be counted and some errors will be associated with this. The smallest dimension of a particle that can be observed and counted meaningfully is about 10 pixels, which is equal to $0.94 \mu \mathrm{m}(10 \times 0.094 \mu \mathrm{m} /$ pixel $)$. The slag used in this study had less than $2 \%$ vol. of particles smaller than $1 \mu \mathrm{m}$ while the Portland cement had less than $5 \%$ vol. of particles smaller than $1 \mu \mathrm{m}$, as measured with laser granulometry. The very small particles are expected to have fully reacted by the time the earliest measurement was made. Thus, the chosen magnification does seem to represent a good compromise between obtaining a good sampling area and adequate resolution. As a possible improvement to the method, point counting can be carried out at higher magnification. However, this gives a smaller field of view and so more frames must be measured. It should also be noted that only one polished sample per mix was imaged in this study, so testing replicates and sampling at different depths is expected to improve accuracy.

Another probable source of error lies in the determination of the evaporable and non-evaporable water contents using the adopted temperatures. It is well-established that dehydration of the C-S-H and ettringite phases occurs at temperatures below $105^{\circ} \mathrm{C}$, thus the measured evaporable water would be over-estimated and correspondingly, the nonevaporable water content underestimated. An alternative method for measuring the water content is by using thermal gravimetric analysis (TGA) to monitor continuously the mass change in the sample as a function of increasing temperature. However, it is very difficult in practice to accurately separate and quantify the various states of water in hydrated cement paste. Recently, it has been shown that ${ }^{1} \mathrm{H}$ NMR is capable of this [35], but it is not yet a widely available technique, requires specialist interpretation and its application is limited for grey cements and certain SCMs because of the effects of iron paramagnetic impurities. In contrast, the oven drying followed by ignition approach is relatively fast, convenient and well-suited for routine application. Although the accuracy of separating the 'evaporable' and the 'non-evaporable' water content at $105^{\circ} \mathrm{C}$ is questionable, this is relatively unimportant for this study since the data are only used to determine the total water content (evaporable plus non-evaporable). Our results show that the total water content was just slightly overestimated, with an overall mean error of $1.5 \%$. The maximum error was 5.5\%. 
Another issue that needs consideration is that carbonates decompose at temperatures beyond $550^{\circ} \mathrm{C}$ and this will cause an over-estimation of the non-evaporable water content. This error can be reduced by avoiding sampling of areas that have been exposed to carbonation or by reducing the maximum ignition temperature to $550^{\circ} \mathrm{C}$ [36]. Another source of error is in the accuracy of the assumed specific volume of non-evaporable water $v_{n}\left(0.72 \mathrm{~cm}^{3} / \mathrm{g}\right)$. If this value changes by $\pm 10 \%$ (i.e. $v_{n}=0.65-0.80 \mathrm{~cm}^{3} / \mathrm{g}$ ), the mean absolute error for the estimated water content, $\mathrm{w} / \mathrm{b}$ and $\mathrm{s} / \mathrm{b}$ ratios for all samples investigated in this study would range from 2.1 to $4.3 \%, 4.7$ to $10.4 \%$ and 7.0 to $10.7 \%$, respectively.

The proposed method assumes that the sample has not experience macroscopic volume change since initial set (Eq. (1)). However, it is known that slag-blended systems can exhibit significantly more drying shrinkage than non-blended systems. The error in the obtained result is expected to include a contribution from shrinkage. However, for application to concrete in real structures, the shrinkage of an unknown concrete would be difficult to ascertain. Thus, it would be instructive to determine the magnitude of error in the estimated $w / b$ and $s / b$ ratios caused by neglecting shrinkage. If shrinkage is considered, then the formula for $\mathrm{w} / \mathrm{b}$ and $\mathrm{s} / \mathrm{b}$ ratios, derived following the same principle can be written as:

$$
\begin{aligned}
& \frac{w}{b}=\frac{V_{W} \rho_{W}}{V_{S} \rho_{S}+V_{C} \rho_{C}}=\frac{V_{W} \rho_{W}}{V_{S} \rho_{S}+\left[1-\left(V_{S}+V_{W}+V_{A}+V_{\varepsilon}\right)\right] \rho_{C}} \\
& \frac{s}{b}=\frac{V_{S} \rho_{S}}{V_{S} \rho_{S}+V_{C} \rho_{C}}=\frac{V_{S} \rho_{S}}{V_{S} \rho_{S}+\left[1-\left(V_{S}+V_{W}+V_{A}+V_{\varepsilon}\right)\right] \rho_{C}}
\end{aligned}
$$

Where $V_{\varepsilon}$ is the volume fraction of shrinkage $\left(\varepsilon_{s}\right)$. The amount of shrinkage that any concrete experiences is influenced by the properties of the concrete (aggregate volume fraction and stiffness, w/b ratio, degree of hydration and slag content) and its environment (humidity, temperature). Hooton et al [37] carried out a literature review of the effect of GGBS on the drying shrinkage of concrete. Data from 62 concrete mixes containing slag from 16 studies were examined, covering concrete mixes with a wide range of w/b ratio ( 0.26 to 0.60 ), slag content ( $20 \%$ to $80 \%$ ), and aggregate content (50-73\% vol). Curing ranged from 3 to 28 days. The measured shrinkage after drying for up to 365 days at $50 \% \mathrm{RH}$ and 20 or $23^{\circ} \mathrm{C}$ was of the order of $\sim 750$ microstrain. This is very consistent with a recent study by Dellinghausen et al. [38] who measured a total shrinkage of no more than 800 microstrain after 365 days of drying at $50 \% \mathrm{RH}, 23^{\circ} \mathrm{C}$ for concretes containing $0-70 \%$ of slag in white and grey Portland cements at $\mathrm{w} / \mathrm{b}$ ratios between 0.3 and 0.55. However, the shrinkage in neat cement paste containing slag will be much higher. Taking an extreme value of $\varepsilon_{\mathrm{s}}$ of 10,000 microstrain $\left(\mathrm{V}_{\varepsilon}=1 \%\right)$ would change the estimated $\mathrm{w} / \mathrm{b}$ and $\mathrm{s} / \mathrm{b}$ ratios by no more than 0.015 and 0.017 respectively for all the samples investigated in this study. Therefore, neglecting shrinkage is another source of error when the method is applied to neat cement pastes. 
A major advantage of the proposed method in relation to existing methods is that it is able to make separate estimations of the original cement, slag and water contents without the need for calibration or reference standards, or requiring the actual chemical composition of the ingredients or prior knowledge of the mix proportions. In addition, the method can be used to simultaneously estimate the degree of reaction of both cement and slag in blended pastes. The specific gravities of slag and Portland cement do not vary significantly and can be taken as 2.90 and 3.15 respectively. The LOI of the binders has to be known to correct for any mass change for the unreacted slag and cement during ignition to $1000^{\circ} \mathrm{C}$. However, this correction is insignificant for mature samples and thus may be omitted without causing large errors. For example, reanalysing our data for the 3-day, 28-day and 1-year old samples but ignoring LOI corrections for the unreacted slag and cement produced average differences of $0.7 \%, 0.4 \%$ and $0.2 \%$, respectively for the volume fraction of water. However, this caused the mean errors of the w/b ratios for the 3-day and 28-day samples to increase significantly, i.e. from $1.2 \%$ to $4.2 \%$ and from $2.3 \%$ to $4.2 \%$, respectively whilst for the 1 -year cured samples, the mean error increased slightly, i.e. from $3.8 \%$ to $4.6 \%$.

In practice, concretes with high w/b ratio will be of most interest in the context of resolving disputes due to suspected non-compliance with mix specification. The presence of aggregates does not influence the method because its volume fraction is constant with time and is measureable with image analysis. However, aggregates will increase the heterogeneity of the paste microstructure so that a larger set of image frames must be analysed to obtain representative results. The volume fraction, specific gravity, water absorption and any loss on ignition of the aggregate will be required so that the relevant corrections can be made in the calculations. Volume fraction can be measured directly with image analysis, while the specific gravity, absorption and LOI can be reasonably estimated from the type and mineralogy of the aggregate, if a sample of the aggregate is not available for direct measurements. Similar corrections will be required if the Portland cement contains blended limestone fines.

In terms of practical application, the method would not yield accurate results if applied to concrete that had experienced significant mechanical damage or chemical deterioration (carbonation) during the period between initial set and the time of testing such that the approximation shown in Eq. (1) no longer applies. Therefore, one must ensure that samples are taken away from the surface zone where these effects may have occurred. This applies to all test methods designed to assess bulk properties of concrete, for example compressive strength. The method is valid for concretes containing 
entrained air or excess voidage, since the amount of air voids can be measured with image analysis and corrections can be made by subtracting the volume fraction of air voids from the measured volume fraction of water to remove any contribution from the air voids during vacuum saturation. The method is also not affected by bleeding or absorption into porous aggregates for calculating the free w/b ratio. However, results from our study [17] show that bleeding and aggregate absorption can significantly reduce the free w/b and so must be accounted for meaningful comparison between the actual w/b ratio and estimated values. The amount of water absorbed by aggregates can be reasonably estimated from the type and mineralogy of the aggregate and hence corrections can be made to the measured water content. Samples that have experienced excessive bleeding will have a more heterogeneous microstructure and show a larger spread in local w/b ratio therefore requiring more image frames to be averaged to obtain accurate point counting results. However, any bleed water that is lost to evaporation would result in the measured water content being lower than expected from the mix proportions. Clearly, more work is needed to test the method on a wider range of samples, to determine its repeatability and reproducibility, in particular for concretes containing slag.

\section{Conclusion}

There is a practical need for a reliable and rapid method for estimating the slag fraction and water/binder ratio in hardened concrete. This paper presents a new microscopy-based method for estimating the original mix composition of hardened slag-blended concretes. The method involves two main measurements: 1) SEM-BSE point counting of the volume fraction of reacted slag, unreacted slag, unreacted cement and air voids, and 2) heating and igniting the samples at $105^{\circ} \mathrm{C}$ and $1000^{\circ} \mathrm{C}$, respectively to establish the evaporable and non-evaporable water contents. The results are then used to calculate the original slag, cement and water contents in the cement paste, thus allowing the w/b and s/b ratios to be established. The main advantage of the method in relation to existing methods is that it does not require comparison to reference standards identical to the unknown samples or prior knowledge of the chemical composition of the binders used. Moreover, the method calculates the degrees of reaction of both cement and slag in blended systems. The method was tested on 60 different samples with a wide range of w/b ratios (0.30 to 0.50$)$, s/b ratios ( 0 to 0.6$)$ and curing ages ( 3 days to 1 year). The results show that the method is very promising. The mean absolute errors for the estimation of slag, water and cement contents were $9.1 \%, 1.5 \%$ and $2.5 \%$, respectively. The mean absolute error for the estimated w/b ratio was $4.7 \%$. Of the 60 samples tested, the largest error in the estimated w/b ratio was $0.046 .91 \%$ of the estimated w/b ratios were within 0.036 of actual values. The results also show that slag had a slight accelerating effect on the hydration of cement at 3 and 28 days, but this became insignificant at 1 year. The degree of reaction of 
slag at 28 days and 1 year increased with increasing w/b ratio. At a constant w/b ratio, the degree of reaction of slag decreased with increasing s/b ratio.

\section{Acknowledgements}

We would like to thank Dr. Alan Poole of the Applied Petrography Group for reviewing an early draft of this manuscript. We would also like to thank the NANOCEM consortium for provision of the cementitious materials and Mr. Andrew Morris for his assistance in sample preparation.

\section{References}

[1] British Standards Institution, BS 1881: Pt 124, Testing concrete. Methods for analysis of hardened concrete, in, BSI, London, 1988.

[2] J. Lay, Analysis of hardened concrete and mortar, in: J. Newman, B.S. Choo (Eds.) Advanced Concrete Technology: Testing and Quality, Elsevier, 2003, pp. 4/2-4/15.

[3] C. Sangha, B. Plunkett, P. Walden, M. Al-Hussaini, Sulphide content variability in cement pastes containing ground granulated blastfurnace slag, Cement and Concrete Research, 22 (1992) 181-185.

[4] J.W. Figg, Analysis of hardened concrete - a guide to tests, procedures and interpretation of results - report of a joint working party of the Concrete Society and Society of Chemical Industry, in, The Concrete Society, London, UK, 1989.

[5] W.J. French, Comments on the determination of the ratio of ggbs to Portland cement in hardened concrete, Concrete, 25 (1991) 33-36.

[6] W.J. French, Concrete petrography: a review, Quarterly Journal of Engineering Geology, 24 (1991).

[7] R. Hooton, C. Rogers, Determination of slag and fly ash content in hardened concrete, Cement, Concrete and Aggregates, 17 (1995) 55-60.

[8] M.G. Grantham, Determination of slag and pulverised fuel ash hardened concrete - The method of last resort revistied, Cement, Concrete and Aggregates, 17 (1995) 76-78.

[9] K. Sisomphon, A chemical analysis method for determining blast-furnace slag content in hardened concrete, Construction and Building Materials, 23 (2009) 54-61.

[10] P. Xie, P. Gu, Y. Fu, J. Beaudoin, Determination of blast-furnace slag content in hardened concrete by electrical conductivity methods, Cement, Concrete and Aggregates, 17 (1995) 79-83.

[11] J.R. McIver, D.E. Davis, A rapid method for the detection and semi-quantitative assessment of milled granulated blastfurnace slag in hardened concrete, Cement and Concrete Research, 15 (1985) 545-548.

[12] A.M. Neville, How closely can we determine the water-cement ratio of hardened concrete, Materials and Structures, 36 (2003) 311-318.

[13] D.A. St John, A.W. Poole, I. Sims, Concrete petrography - A handbook of investigative techniques, Bookcraft (Bath) Ltd, Somerset, 1998.

[14] Nordtest Method, NT Build 361-1999, Concrete, Hardened: Water-Cement Ratio. 2nd Ed., in, Nordic Innovations Centre, Oslo, 1999. 
[15] M.A. Eden, A code of practice for the petrographic examination of concrete, in, Applied Petrography Group, Special Report 2, 2010.

[16] H.S. Wong, N.R. Buenfeld, Determining the water-cement ratio, cement content, water content and degree of hydration of hardened cement paste: Method development and validation on paste samples, Cement and Concrete Research, 39 (2009) 957-966.

[17] H.S. Wong, N.R. Buenfeld, Estimating the original cement content and water-cement ratio (w/c) of Portland cement concrete and mortar using backscattered electron microscopy, Mag Concr Res, 65 (2013) 693-706.

[18] ASTM C114 - 11b, Standard test methods for chemical analysis of hydraulic cement, in, ASTM International, West Conshohocken, PA, 2011.

[19] H.S. Wong, N.R. Buenfeld, Patch microstructure in cement-based materials: Fact or artefact?, Cement and Concrete Research, 36 (2006) 990-997.

[20] H.S. Wong, N.R. Buenfeld, Monte Carlo simulation of electron-solid interactions in cement-based materials, Cement and Concrete Research, 36 (2006) 1076-1082.

[21] V. Kocaba, E. Gallucci, K.L. Scrivener, Methods for determination of degree of reaction of slag in blended cement pastes, Cement and Concrete Research, 42 (2012) 511-525.

[22] P. Stutzman, Scanning electron microscopy imaging of hydraulic cement microstructure, Cem Concr Comp, 26 (2004) 957-965.

[23] A.P. Barker, An electron optical examination of zoning in blastfurnace slag hydrates: Part 1. Slag cement pastes at early ages, Adv Cem Res, 2 (1989) 171-179.

[24] A.M. Harrisson, N.B. Winter, H.F.W. Taylor, Microstructure and microchemistry of slag cement pastes, in: Mat Res Soc Symp Proc, 1987, pp. 213-222.

[25] I.G. Richardson, G.W. Groves, Microstructure and microanalysis of hardened cement pastes involving ground granulated blast furnace slag, J Mater Sci, 27 (1992) 6204-6212.

[26] H. Brouwers, The work of Powers and Brownyard revisited: Part 2., Cement and Concrete Research, 35 (2005) 1922-1936.

[27] T.C. Powers, T.L. Brownyard, Studies of the physical properties of hardened Portland cement paste, Bull 22, Res Lab of Portland Cement Association, Skokie, IL, USA, reprinted from J Am Concr Inst (Proc), 43 (1947) $101-249$.

[28] J.-I. Escalante-Garcia, J. Sharp, The chemical composition and microstructure of hydration products in blended cements, Cement and Concrete Composites, 26 (2004) 967-976.

[29] R. Taylor, I.G. Richardson, R.M.D. Brydson, Composition and microstructure of 20-year-old ordinary Portland cement-ground granulated blast-furnace slag blends containing 0 to $100 \%$ slag, Cement and Concrete Research, 40 (2010) 971-983.

[30] B. Lothenbach, K. Scrivener, R.D. Hooton, Supplementary cementitious materials, Cement and Concrete Research, 41 (2011) 1244-1256.

[31] J. Lumley, R. Gollop, G. Moir, H. Taylor, Degrees of reaction of the slag in some blends with Portland cements, Cement and Concrete Research, 26 (1996) 139-151.

[32] J. Escalante-Garcia, J. Sharp, Effect of temperature on the hydration of the main clinker phases in Portland cements: Part II, blended cements, Cement and Concrete Research, 29 (1998) 1259-1274.

[33] J.I. Escalante, L.Y. Gomez, K.K. Johal, G. Mendoza, H. Mancha, J. Mendez, Reactivity of blast-furnace slag in Portland cement blends hydrated under different conditions, Cement and Concrete Research, 31 (2001) 1403-1409.

[34] X. Feng, E. Garboczi, D. Bentz, P. Stutzman, T.O. Mason, Estimation of the degree of hydration of blended cement pastes by a scanning electron microscope point-counting procedure, Cement and Concrete Research, 34 (2004) 1787-1793.

[35] A. Valori, P.J. McDonald, K.L. Scrivener, The morphology of C-S-H: Lessons from 1H nuclear magnetic resonance relaxometry, Cement and Concrete Research, 49 (2013) 65-81.

[36] K. De Weerdt, M.B. Haha, G. Le Saout, K.O. Kjellsen, H. Justnes, B. Lothenbach, Hydration mechanisms of ternary Portland cements containing limestone powder and fly ash, Cement and Concrete Research, 41 (2011) $279-291$.

[37] R. Hooton, K. Stanish, J. Angel, J. Prusinski, The Effect of Ground Granulated Blast Furnace Slag (Slag Cement) on the Drying Shrinkage of Concrete-A Critical Review of the Literature, ACI Special Publication, 263 (2009). 
[38] L.M. Dellinghausen, A.L.G. Gastaldini, F.J. Vanzin, K.K. Veiga, Total shrinkage, oxygen permeability, and chloride ion penetration in concrete made with white Portland cement and blast-furnace slag, Construction and Building Materials, 37 (2012) 652-659. 